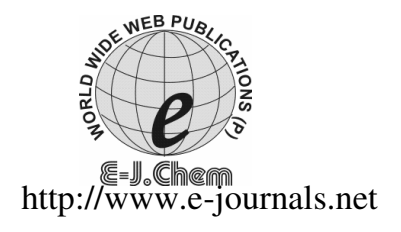

\title{
Simultaneous Estimation of Glimepiride, Rosiglitazone and Pioglitazone Hydrochloride in the Pharmaceutical Dosage Form
}

\author{
FREDDY H. HAVALDAR* ${ }^{*}$ and DHARMENDRA L.VAIRAL \\ Nadkarny-Sacasa Research Laboratory, Department of Chemistry, \\ St.Xavier's College, Mumbai - 400 001, India. \\ vairal21@yahoo.com
}

Received 5 February 2010; Accepted 2 April 2010

\begin{abstract}
A simple, specific, accurate and economical gradient reversed phase liquid chromatographic (RP-HPLC) method was developed and subsequently validated for the determination of glimipiride, rosiglitazone and pioglitazone hydrochloride. Separation was achieved with a nucleodur C-18 column having $250 \times 4.6 \mathrm{~mm}$ i.d. with $5 \mu \mathrm{m}$ particle size and water HPLC grade adjusted to $\mathrm{pH} 3.0$ using diluted orthophosphoric acid and acetonitrile $(80: 20 \mathrm{v} / \mathrm{v})$ with gradient program as eluent at a constant flow rate of $0.8 \mathrm{ml}$ per min. UV detection was performed at $215 \mathrm{~nm}$. The retention time of glimipiride, rosiglitazone and pioglitazone hydrochloride were about $17.9 \mathrm{~min}, 6.31 \mathrm{~min}$ and $8.24 \mathrm{~min}$ respectively. This method is simple, rapid and selective and can be used for routine analysis of antidiabetic drugs in pharmaceutical preparation. The proposed method was validated and successfully used for estimation of glimipiride, rosiglitazone and pioglitazone hydrochloride in the pharmaceutical dosage form.
\end{abstract}

Keywords: Validation, RP-HPLC, Glimipiride (GLI), Rosiglitazone (ROSE), Pioglitazone hydrochloride (PIO).

\section{Introduction}

The purpose of this method is to develop the reversed phase liquid chromatographic technique (RP-HPLC) method for simultaneous determination of antidiabetic drugs glimipiride, rosiglitazone and pioglitazone hydrochloride in pharmaceutical formulations. It is essential to have a validated, stability indicated or specific analytical method of analysis for the drug for which the drug delivery system is to be designed. If the suitable analytical method is not available then it is essential to develop a simple, specific, accurate and economical analytical method for the selected drug to aid during various steps of formulation design. Reversed phase liquid chromatographic technique (RP-HPLC) is one of the latest and most widely applied techniques for drug estimation. This method is simple, rapid and selective. The proposed method was validated and successfully used for determination of 
glimipiride, rosiglitazone and pioglitazone hydrochloride in the pharmaceutical dosage form. A literature survey regarding quantitative analysis of these drugs revealed that attempts were made to develop analytical methods for glimipiride, rosiglitazone and pioglitazone hydrochloride using spectrophotometry $^{1-3}$, high performance liquid chromatography (HPLC) ${ }^{4-20}$, have been reported for the determination of glimipiride, rosiglitazone and pioglitazone hydrochloride. LC-MS/MS ${ }^{21}$ and LC - electrospray tandem mass spectrometry ${ }^{22-24}$ have been reported for determination of glimipiride, rosiglitazone and pioglitazone hydrochloride. Glimipiride is official in pharmacopoeia and high performance liquid chromatography (HPLC) method had been reported for its estimation. This paper describes a new reversed phase high performance liquid chromatography (RP-HPLC) method for the estimation of glimepiride, rosiglitazone and pioglitazone hydrochloride combination in mixture using simple mobile phase.

\section{Experimental}

The liquid chromatographic system consists of the following components: Agilent HPLC model (1100 series) containing quaternary pump, sample thermostat, column thermostat, thermostated autosampler and variable wavelength programmable detector. Chromatographic analysis was performed using Chemstation software on a Nucleodur C-18 column with 250x4.6 mm i.d. and $5 \mu \mathrm{m}$ particle size. The Metter Telledo electronic balance (AX 105) was used for weighing purpose. Analytically pure Glimepiride, Rosiglitazone and Pioglitazone hydrochloride were obtained as gift samples from my colleague Mr.Haresh Gurav (Asst.Manager QA/RA Dept. -Nicholas Piramal India Ltd. Mumbai, India). Acetonitrile, methanol (E.Merck, Mumbai, India), water (TKA water purification system Germany) were of HPLC grade and ortho phosphoric acid (S.D. Fine Chemicals, Mumbai, India) were of analytical grade used for the preparation of mobile phase. Three commercial formulations each of Glimepiride (Glimetop-1 Tablets, USV Limited. Mumbai, India), Rosiglitazone (Reglit Tablets, Dr.Reddy's Laboratories Limited. Hyderabad, India) and Pioglitazone hydrochloride (Daivista Tablets, Dr.Reddy's Laboratories Limited. Hyderabad, India) were selected from local market on random basis.

\section{Preparation of reagent and solution}

Water HPLC grade. Finally the $\mathrm{pH} 3.0$ was adjusted with diluted ortho phosphoric acid. The mobile phase solution was sonicated for about 10 minutes and filtered through $0.45 \mu$ filter paper.

Mobile phase composition: 80 volume of water and 20 volume of acetonitrile. Using linear gradient program. Glimepiride, rosiglitazone and pioglitazone hydrochloride were weighed $(50 \mathrm{mg}$ of each) and transferred to three separate $50 \mathrm{~mL}$ of volumetric flasks and dissolved in water: acetonitrile (1:1) which gives $1000 \mu \mathrm{g} / \mathrm{mL}$ of glimepiride (GLI), rosiglitazone (ROSE) and pioglitazone (PIO) hydrochloride respectively. These stock solutions were further diluted with water: acetonitrile (1:1) to obtain final concentration of $100 \mu \mathrm{g} / \mathrm{mL}$.

\section{Optimization of experimental condition}

A linear gradient reversed phase C-18 column equilibrated with mobile phase wateracetonitrile (80:20) was used with gradient program initial 80: 20 at $20 \mathrm{~min}$. 20: 80 at $21 \mathrm{~min}$. $80: 20$ and stable up to $30 \mathrm{~min}$. with $80: 20$ ratio. Mobile phase flow rate was maintained at $0.8 \mathrm{~mL}$ per min. and effluents were monitored at $215 \mathrm{~nm}$. The sample was injected using a $10 \mu \mathrm{L}$ fixed loop and the total run time was $30 \mathrm{~min}$. Appropriate aliquots of glimepiride, rosiglitazone and pioglitazone hydrochloride stock solutions were taken in $10 \mathrm{~mL}$ volumetric flasks and diluted up to the mark with diluent to obtain final concentration of 50, $75,100,125,150 \mu \mathrm{g} / \mathrm{mL}$ of glimepiride, rosiglitazone and pioglitazone hydrochloride respectively. The solutions were injected using $10 \mu \mathrm{L}$ fixed loop system and chromatograms 
were recorded. Calibration curves were constructed by plotting average peaks versus concentrations. Correlation coefficients were computed for glimepiride, rosiglitazone and pioglitazone hydrochloride.

\section{Limit of detection and limit of quantification}

A calibration curve was prepared using concentrations in the range of $0.05-0.150 \mathrm{mg} / \mathrm{mL}$ for glimepiride, rosiglitazone and pioglitazone hydrochloride. The standard deviations of $y$-intercepts of regression lines were determined and kept in the following equation for the determination of detection limit and quantitation limit. Detection limit $=3.3 \sigma / \mathrm{s}$; quantitation limit $=10 \sigma / \mathrm{s}$; where in $\sigma$ is standard deviation of $y$-intercepts of regression lines and $\mathrm{s}$ is the slope of the calibration curve. Detection limit and quantitation limit can also be estimated using signal to noise and relative standard deviation method.

\section{Linearity studies}

The content of twenty tablets were taken and weighed. Powder equivalent to $50 \mathrm{mg}$ of glimepiride, rosiglitazone and pioglitazone hydrochloride respectively were accurately weighed and transferred to three separate $100 \mathrm{~mL}$ volumetric flasks and $50 \mathrm{~mL}$ of diluent was added to the same and the flasks were sonicated for $15.0 \mathrm{~min}$. The flasks were shaken and the volume was diluted up to the mark with the same mixture. The above solution was filtered using Whatman filter paper (No.1). Appropriate volume of the aliquots of glimepiride, rosiglitazone and pioglitazone hydrochloride stock solutions were taken in different $10 \mathrm{~mL}$ volumetric flasks and the volume was made up to the mark with diluent to obtain final concentration of $50,75,100,125,150 \mu \mathrm{g} / \mathrm{mL}$ of glimepiride, rosiglitazone and pioglitazone hydrochloride respectively. The solutions were sonicated for $5.0 \mathrm{~min}$. The solutions were injected at above chromatographic conditions and peak areas were measured. Calibration curves were constructed by plotting the average peak areas versus concentrations.

\section{Precision and accuracy of method (Recovery studies)}

\section{Glimepiride}

The content of twenty tablets of glimetop- 1 were taken and weighed. Powder equivalent to $50 \mathrm{mg}$ of glimepiride was accurately weighed and transferred to $50 \mathrm{~mL}$ volumetric flask and $30 \mathrm{~mL}$ of diluent was added to the same and flask was sonicated for $15.0 \mathrm{~min}$. The flask was shaken and the volume was diluted up to the mark with the same mixture. The above solution was filtered using Whatman filter paper (No.1). Appropriate volume of the aliquot of glimepiride stock solution was taken in different $100 \mathrm{~mL}$ volumetric flasks and the final volume was made up to the mark with diluent to obtain 120,100 and $80 \mu \mathrm{g} / \mathrm{mL}$ of glimepiride. The drug content per tablets of the above brand of glimepiride was calculated from the absorbance values obtained (taking average of three determinations).

\section{Rosiglitazone}

The content of twenty tablets of REGLIT were taken and weighed. Powder equivalent to $50 \mathrm{mg}$ of rosiglitazone was accurately weighed and transferred to $50 \mathrm{~mL}$ volumetric flask and $30 \mathrm{~mL}$ of diluent was added to the same and flask was sonicated for $15.0 \mathrm{~min}$. The flask was shaken and the volume was diluted up to the mark with the same mixture. The above solution was filtered using Whatman filter paper (No.1). Appropriate volume of the aliquot of rosiglitazone stock solution was taken in different $100 \mathrm{~mL}$ volumetric flasks and the final volume was made up to the mark with diluent to obtain 120,100 and $80 \mu \mathrm{g} / \mathrm{mL}$ of rosiglitazone. The drug content per tablets of the above brand of rosiglitazone was calculated from the absorbance values obtained (taking average of three determinations). 


\section{Pioglitazone hydrochloride}

The content of twenty tablets of DAIVISTA were taken and weighed. Powder equivalent to $50 \mathrm{mg}$ of pioglitazone hydrochloride was accurately weighed and transferred to $50 \mathrm{~mL}$ volumetric flask and $30 \mathrm{~mL}$ of diluent was added to the same and flask was sonicated for $15.0 \mathrm{~min}$. The flask was shaken and the volume was diluted up to the mark with the same mixture. The above solution was filtered using Whatman filter paper (No.1). Appropriate volume of the aliquot of pioglitazone hydrochloride stock solution was taken in different $100 \mathrm{~mL}$ volumetric flasks and the final volume was made up to the mark with diluent to obtain 120,100 and $80 \mu \mathrm{g} / \mathrm{mL}$ of pioglitazone hydrochloride. The drug content per tablets of the above brand of pioglitazone hydrochloride was calculated from the absorbance values obtained (taking average of three determinations). The accuracy of the method was determined by calculating recoveries of glimepiride, rosiglitazone and pioglitazone hydrochloride using standard solutions.

\section{Results and Discussion}

Optimization of mobile phase or chromatographic condition was performed based on resolution, tailing factor, symmetric factor and peak areas obtained for glimepiride, rosiglitazone and pioglitazone hydrochloride are shown in Table 1. The data of regression analysis of the glimepiride was found to be linear with correlation coefficient (r) $=1.000$. Similarly the calibration curves for rosiglitazone and pioglitazone hydrochloride were found to be linear with correlation coefficient $(r)=0.998$ and 0.999 respectively are shown in Table 2 . The mobile phase water HPLC grade adjusted to $\mathrm{pH} 3.0$ using diluted orthophosphoric acid and acetonitrile in the composition (80:20) with linear gradient was found to be satisfactory. These mobile phase composition gave symmetric and well-resolved peaks for glimepiride, rosiglitazone and pioglitazone hydrochloride. The resolution between the rosiglitazone and pioglitazone hydrochloride was found 5.58 and resolution between pioglitazone hydrochloride and glimepiride was found 38.4, which indicates good separation of these three compounds.

Table 1. Optimization of experimental conditions

\begin{tabular}{ll}
\hline \multicolumn{1}{c}{ Parameters } & \multicolumn{1}{c}{ Optimized condition } \\
\hline Chromatograph & Agilent HPLC \\
Column & Nucleodur C-18,250 x $4.6 \mathrm{~mm}, 5 \mu \mathrm{m}$ \\
& Water HPLC grade $\mathrm{pH}-3.0:$ Acetonitrile \\
Mobile phase & $(80: 20 \mathrm{v} / \mathrm{v})$ with linear gradient program. \\
Flow rate & $0.8 \mathrm{~mL}$ per min. \\
Detection & $\mathrm{UV}$ at $215 \mathrm{~nm}$ \\
Injection volume & $10 \mu \mathrm{L}$ \\
Temperature & Ambient \\
Run Time & $30.0 \mathrm{~min}$. \\
Retention time - GLI & $17.9 \mathrm{~min}$. \\
Retention time - ROSE & $6.31 \mathrm{~min}$. \\
Retention time - PIO & 8.24 min. \\
\hline PLC grade filtered through a $0.45 \mu$ membrane filter (Millipore), degassed and sonicated
\end{tabular}

Table 2. Regression analysis of the calibration curves for the proposed method

\begin{tabular}{lccc}
\hline \multicolumn{1}{c}{ Parameters } & GLI & ROSE & PIO \\
\hline Linearity range, $\mu \mathrm{g} / \mathrm{mL}$ & $50-150$ & $50-150$ & $50-150$ \\
Slope & 27896.8 & 18014.8 & 27213.2 \\
Intercept & 644.94 & 715.45 & 650.57 \\
Standard deviation of slope & 1619.1 & 1188.5 & 1589.5 \\
Regression $\left(\mathrm{R}^{2}\right)$ & 0.9999 & 0.9961 & 0.9998 \\
Correlation coefficient $(\mathrm{r})$ & 1.000 & 0.998 & 0.999 \\
\hline
\end{tabular}


The retention time for glimepiride, rosiglitazone and pioglitazone hydrochloride were about $17.9 \mathrm{~min}, 6.31 \mathrm{~min}$ and $8.24 \mathrm{~min}$ respectively (Figure 1). The symmetric factors for glimepiride, rosiglitazone and pioglitazone hydrochloride were $0.91,0.43$ and 0.53 respectively. Overlain UV spectra of glimepiride, rosiglitazone and pioglitazone hydrochloride showed that these drugs absorbs appreciably at $215 \mathrm{~nm}$. Hence $215 \mathrm{~nm}$ was selected as the detection wavelength in the liquid chromatography (Figures 2 and 3).

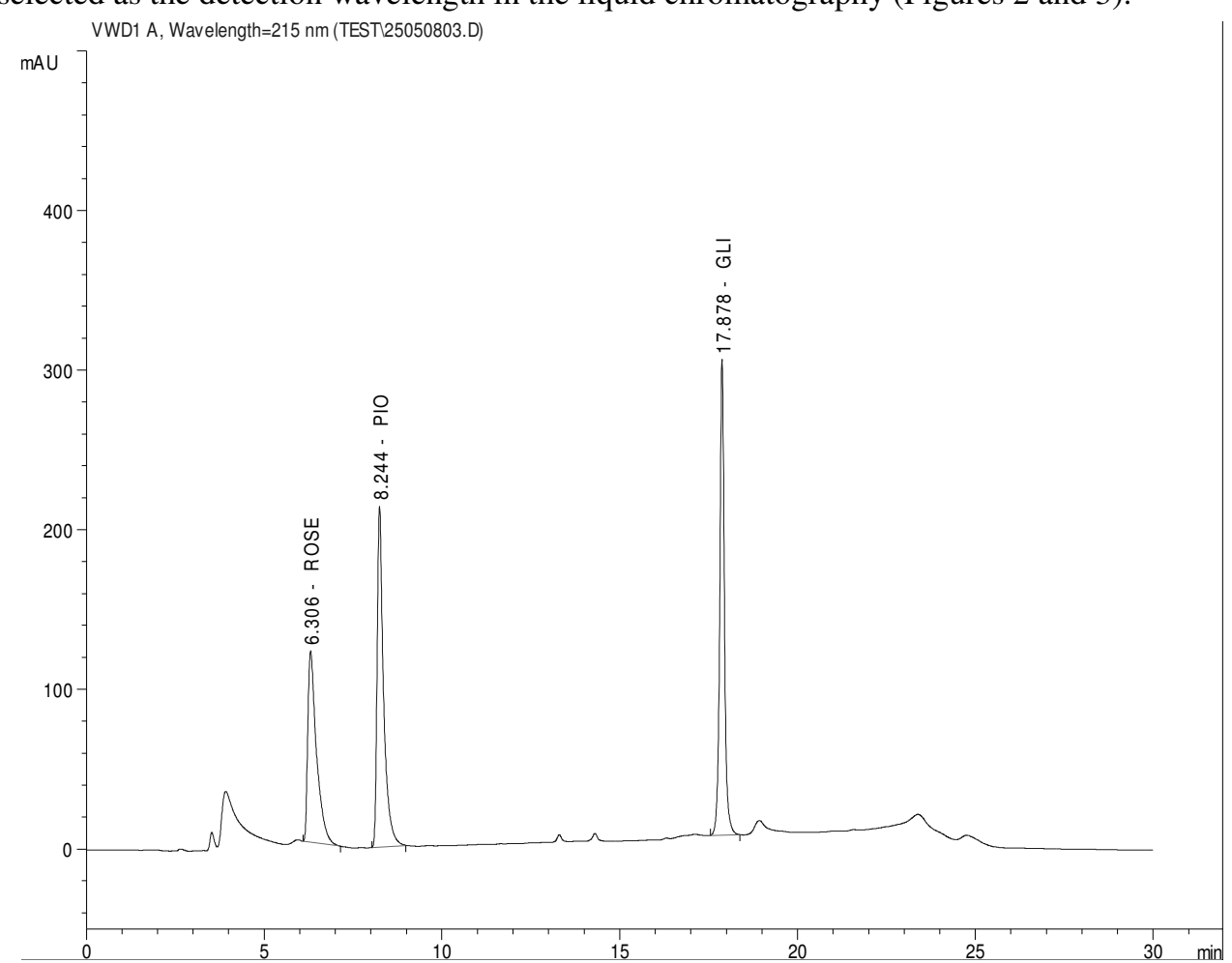

Figure 1. Typical HPLC chromatogram of GLI, ROSE and PIO Chromatogram showing well resolved peaks of GLI, ROSE and PIO

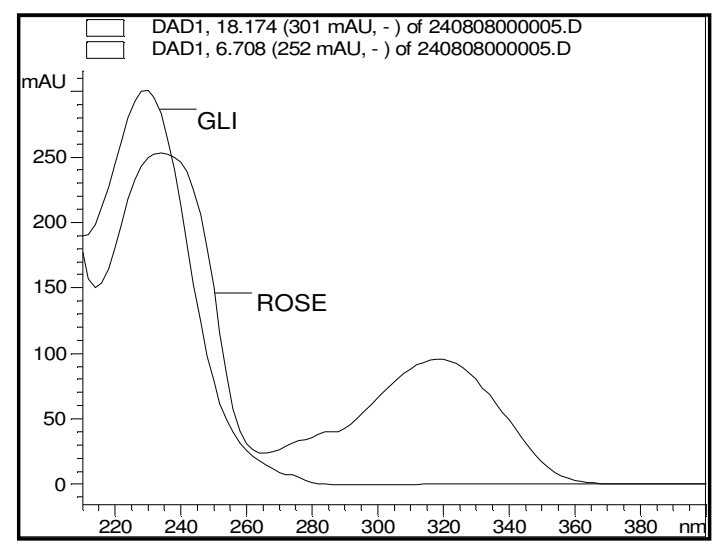

Figure 2. UV overlain spectra of GLI and ROSE 


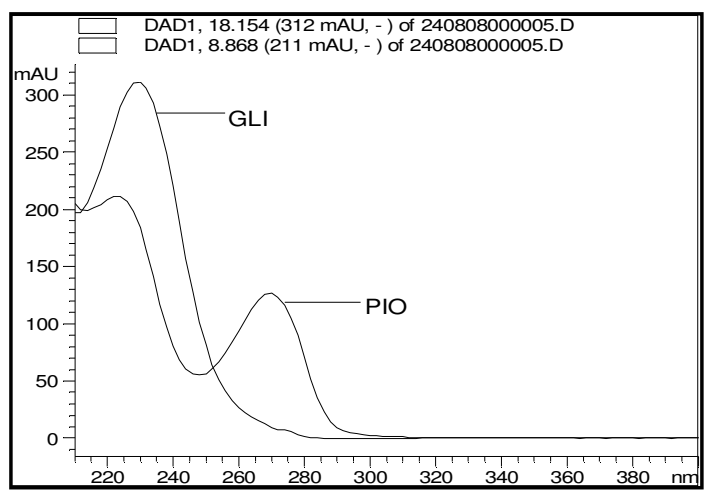

Figure 3. UV overlain spectra of GLI and PIO

The detection limits for glimepiride, rosiglitazone and pioglitazone hydrochloride were $0.19 \mu \mathrm{g}$ per $\mathrm{mL} .0 .22 \mu \mathrm{g}$ per $\mathrm{mL}$ and $0.19 \mu \mathrm{g}$ per $\mathrm{mL}$ respectively. The quantification limit for glimepiride, rosiglitazone and pioglitazone hydrochloride were $0.58 \mu \mathrm{g}$ per $\mathrm{mL}, 0.66 \mu \mathrm{g}$ per $\mathrm{mL}$ and $0.58 \mu \mathrm{g}$ per $\mathrm{mL}$ respectively, which suggest that these compounds can be estimated accurately. The system suitability parameters are summarized in Table 3 . The calibration curves for glimepiride, rosiglitazone and pioglitazone hydrochloride were obtained by plotting the peak areas of glimepiride, rosiglitazone and pioglitazone hydrochloride versus concentrations over a range of $50,75,100,125$ and $150 \mu \mathrm{g} / \mathrm{mL}$ of glimepiride, rosiglitazone and pioglitazone hydrochloride respectively are shown in Table 4.

Table 3. System suitability parameter

\begin{tabular}{cccc}
\hline Parameters & GLI & ROSE & PIO \\
\hline Linearity range, $\mu \mathrm{g} / \mathrm{mL}$ & $50-150$ & $50-150$ & $50-150$ \\
Theoretical plates (meter) & 394761 & 15055 & 50785 \\
Resolution & 38.4 & --- & 5.58 \\
Tailing factor & 1.09 & 1.97 & 1.79 \\
Symmetry factor & 0.91 & 0.43 & 0.53 \\
Detection limit, $\mu \mathrm{g} / \mathrm{mL}$ & 0.19 & 0.22 & 0.19 \\
Quantification limit, $\mu \mathrm{g} / \mathrm{mL}$ & 0.58 & 0.66 & 0.58 \\
\hline
\end{tabular}

Table 4. Linearity or calibration curves

\begin{tabular}{cccccc}
\hline \multicolumn{2}{c}{ GLI } & \multicolumn{2}{c}{ ROSE } & \multicolumn{2}{c}{ PIO } \\
\hline Con.ppm & Av.Area & Con.ppm & Av.Area & Con.ppm & Av.Area \\
50 & 1348.9 & 50 & 1132.0 & 50 & 1329.2 \\
75 & 2041.9 & 75 & 1611.3 & 75 & 2024.3 \\
100 & 2719.5 & 100 & 2129.8 & 100 & 2668.2 \\
125 & 3437.5 & 125 & 2540.4 & 125 & 3386.2 \\
150 & 4138.2 & 150 & 2919.3 & 150 & 4049.9 \\
\hline
\end{tabular}

Glimepiride was found to be linear with regression $\left(R^{2}\right)=1.000$. Similarly the calibration curves for rosiglitazone and pioglitazone hydrochloride were found to be linear with regression $\left(R^{2}\right)=0.996$ and 0.999 respectively shown in (Figure 4, 5 and 6). The recovery studies of glimepiride, rosiglitazone and pioglitazone hydrochloride were found in the range of 99.9 to $100.1,100.0$ to 100.2 and 100.2 to $100.3 \%$ respectively. The recovery of glimepiride was found in tablets in the range of $0.999 \mathrm{mg}$ to $1.000 \mathrm{mg}$. 


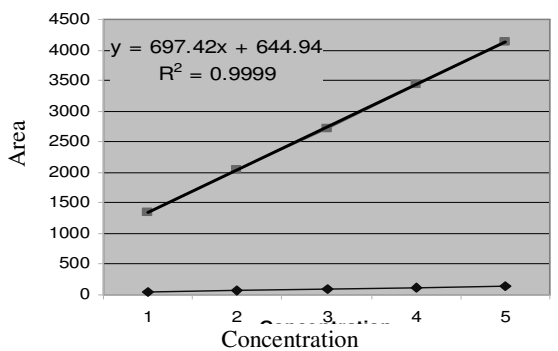

Figure 4. Linearity of GLI GLI is Glimepiride

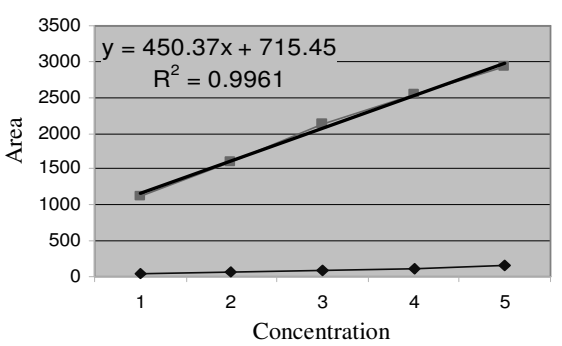

Figure 5. Linearity of ROSE

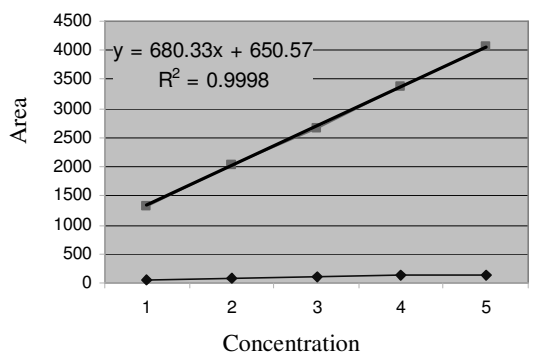

Figure 6. Linearity of PIO

The recovery of rosiglitazone was found in the range of $4.00 \mathrm{mg}$ to $4.01 \mathrm{mg}$ and pioglitazone hydrochloride was found in the range of $30.06 \mathrm{mg}$ to $30.09 \mathrm{mg}$. The chromatographic method was applied to the determination of glimepiride, rosiglitazone and pioglitazone hydrochloride in their pharmaceutical dosage form. The results for glimepiride, rosiglitazone and pioglitazone hydrochloride were comparable with their corresponding labeled amounts are shown in Table 5.

Table 5. Assay of combined dosage form and recovery studies

\begin{tabular}{ccccc}
\hline Drugs & Level & $\begin{array}{c}\text { Average assay } \\
\text { Recovery, } \%\end{array}$ & $\begin{array}{c}\text { Amount obtained } \\
\text { mg per tablets }\end{array}$ & $\begin{array}{c}\text { Labeled amount } \\
\text { mg per tablets }\end{array}$ \\
\hline GLI & I & 100.1 & 1.00 & 1.0 \\
& II & 99.9 & 0.999 & \\
ROSE & III & 100.1 & 1.00 & 4.0 \\
& I & 100.2 & 4.01 & \\
& II & 100.0 & 4.00 & 30.0 \\
PIO & III & 100.0 & 4.00 & \\
& I & 100.2 & 30.06 & \\
& II & 100.2 & 30.06 & \\
\hline
\end{tabular}

\section{Conclusion}

We have successfully developed a new RP-HPLC method for the estimation of glimepiride, rosiglitazone and pioglitazone hydrochloride were found to be simple, economical and useful with high accuracy, precision and low detection limit and quantitation limit. Rapidity and capability of quantifying very low concentration of respective drugs, made them useful for variety of analyses, including pure drug analysis, assay of formulations and stability studies analysis. The proposed methods did not utilize any extraction step for recovering the 
drug from the formulation excipient matrixes and their by decreased the degree of error, time in estimation of drugs and the overall cost of the analysis. The solvent system used was simple mobile phase compared to the reported method. The method gives good resolution between glimepiride, rosiglitazone and pioglitazone hydrochloride. The method was validated and found to be simple, sensitive, accurate, precise and economical. Percentage of assay recovery shows that the method is free from interference of the excipients used in the formulation. Therefore, the proposed method can be used for routine analysis of glimepiride, rosiglitazone and pioglitazone hydrochloride in their pharmaceutical dosage form.

\section{Acknowledgments}

I thank my friend Mr.Haresh Gurav (M/s Nicholas Piramal India Limited, Mumbai, India) for providing me the gift samples of glimepiride, rosiglitazone and pioglitazone hydrochloride.

\section{References}

1. Gomes P and Steppe M, J AOAC International, 2006, 89(5), 1296-1299.

2. Altinoz S and Tekeli D, J Pharma Biomed Anal., 2001, 24, 507-515.

3. Patrica Gomes and Martin Steppe, J AOAC Int., 2006, 89, 5.

4. Radhakrishna T, Satyanarayana J and Satyanarayana A, J Pharma Biomed Anal., 2002, 29, 873.

5. Kolte B L, Raut B B, Deo A A, Bagool M A and Shinde D B, J Chromatogr Sci., 2004, 42, 27.

6. Venkatesh P, Harisudhan T, Hira Choudhury, Ramesh Mullangi, Nuggehally and Srinivas R, Biomed Chromatogr., 2006.

7. Zhong W Z and Lakings D B, J Chromatogr., 1989, 490, 377.

8. Yamashita K, Murakami H, Okuda T and Motohashi M, J Chromatogr B Biomed Appl., 1996, 677, 144-146.

9. AbuRuz, S Millership J and McElnay J, J Chromatogr B., 2005, 817, 277.

10. Pattana Sripalakit, Penorn Neamhom and Aurasorn Saraphanchotiwitthaya, $J$ Chromatogr B., 2006, 843, 164.

11. Ceren Yardimera, Nuran Ozaltma and Alper Gurlek, Talanta, 2007, 72, 1416-1422.

12. Jing Yao, Ya-Qin Shi, Zhuo-Rong Li and Shao-Hong Jin, J Chromatogr B., 2007, 853, 254.

13. Wanjari D B and Gaikwad N J, Indian J Pharm Sci., 2005, 67, 253.

14. Wanjari D B and Gaikwad N J, Indian J Pharm Sci., 2005, 67, 256.

15. Khan M A, Sinha S, Vartak S, Bhartiya A and Kumar S, J Pharma Biomed Anal., 2005, 39, 928.

16. El Deeb S, Schepers U and Watzig H, J Sep Sci., 2006, 29, 1571.

17. Jedlicka A, Klimes J and Grafnetterova T, Pharmazie, 2004, 59, 178.

18. Collin F, Khoury H, Bonnefont Rousselot D, Therond P, Legrand A, Jore D, Gardes M, Albert, Rapid Commun Mass Spectrom., 2004, 39, 890.

19. Osadebe P O, Akabogu I C, Oll Chim Farm, 2004, 143, 170.

20. Matthew W Hruska and Reginald F Frye, J Chromatogr B., 2004, 803, 317-320.

21. He J, Hu Y F, Duan L F, Tan Z R, Wang L S, Wang D, Zhang W, Li Z, Liu J, Tu J H, Yao Y M and Hong-Hao Zhou, J Pharma Biomed Anal., 2007, 43.

22. Lu Zhang, Yuan Tian, Zunjian Zhang and Yun Chen, J Chromatogr B, 2007, 854, 91.

23. Emmie N M Ho, Kenneth C H Yiu, Terence S M Wan, Brian D Stewart and Keith L Watkins, J Chromatogr B., 2004, 811, 65.

24. Yannis Dotsikas, Constantinos Kousoulos, Georgia Tsatsou and Yannis L Loukas, Rapid Commun Mass Spectrom., 2005, 19, 2055. 


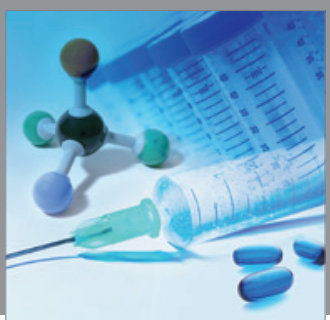

International Journal of

Medicinal Chemistry

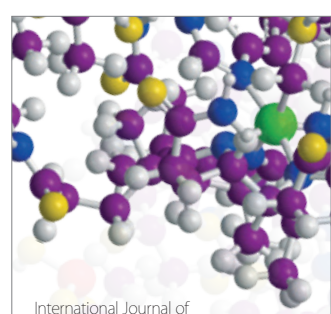

Carbohydrate Chemistry

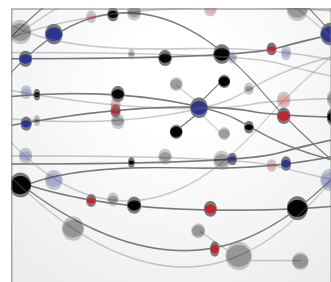

The Scientific World Journal
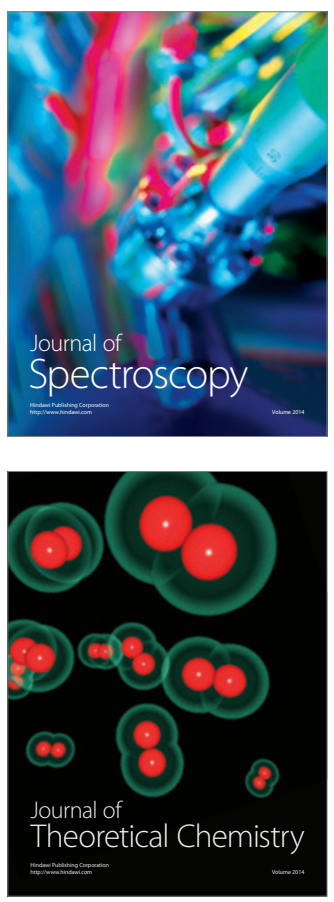
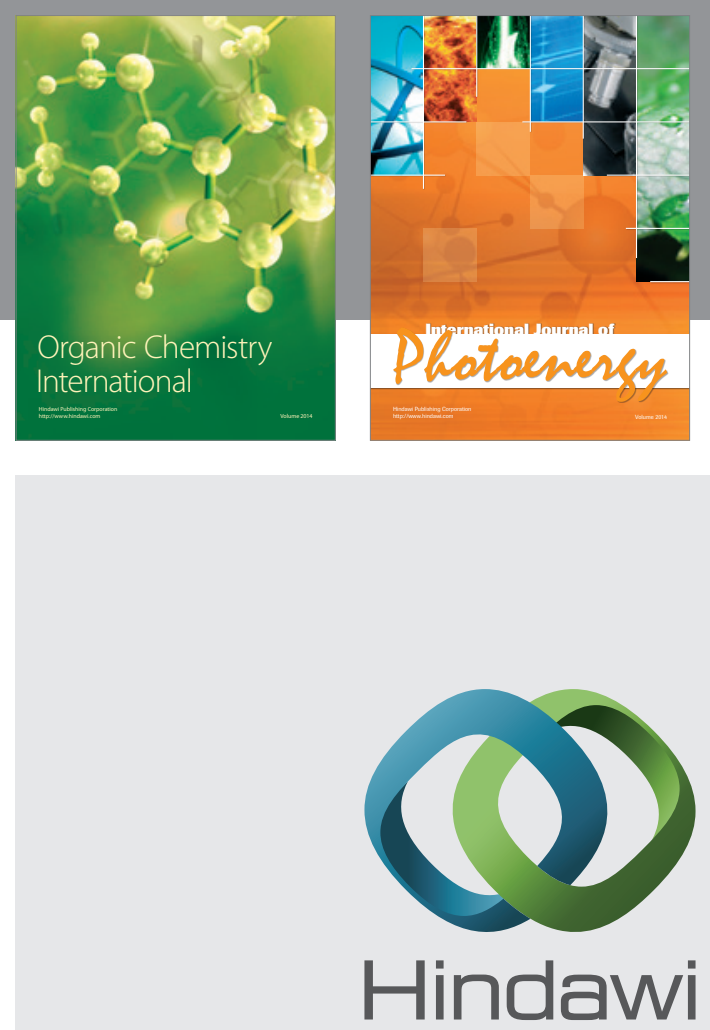

Submit your manuscripts at

http://www.hindawi.com
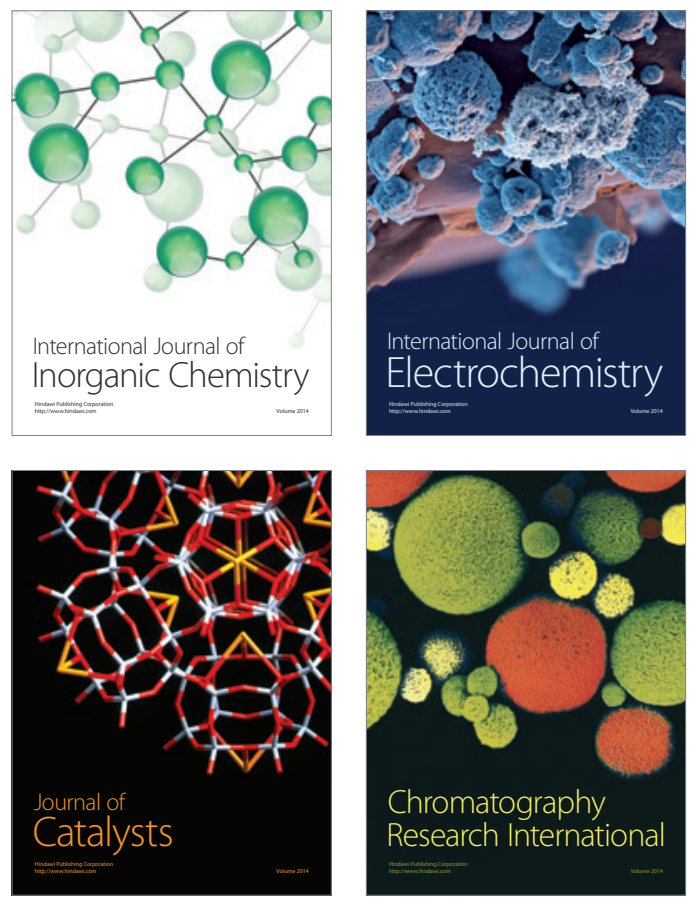
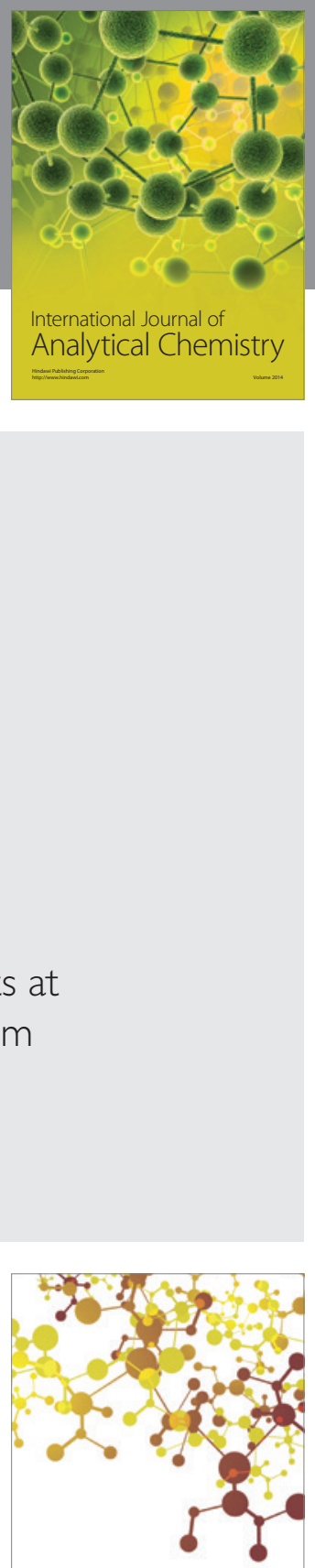

Journal of

Applied Chemistry
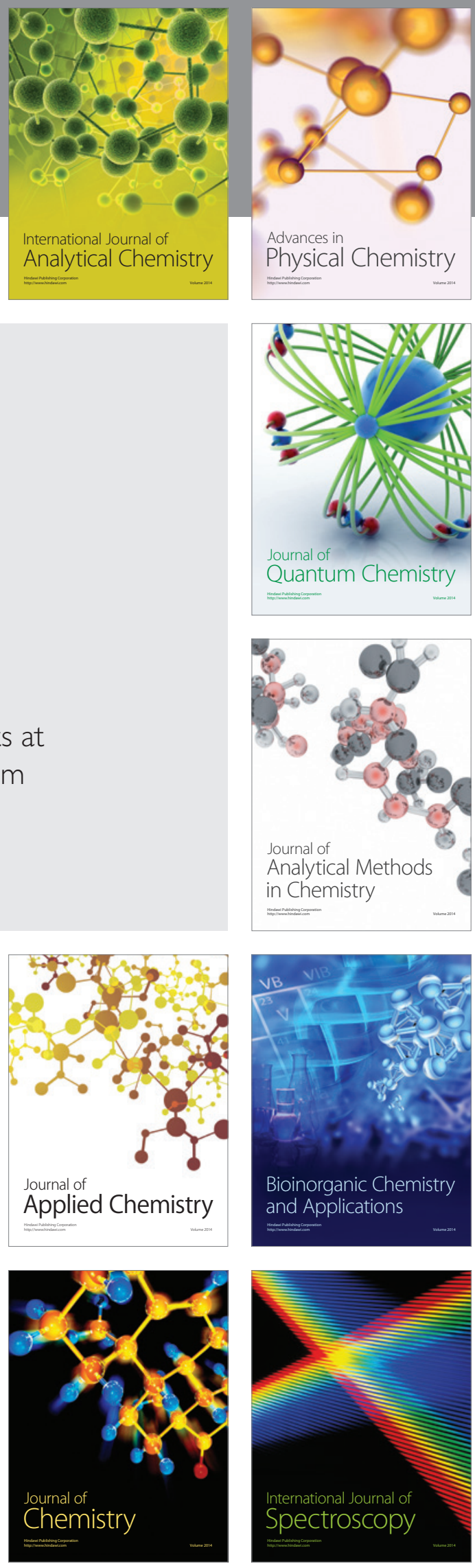